\title{
Involvement of Dipeptidyl Peptidase IV in Immune Complex-Mediated Glomerulonephritis
}

\author{
Toshihiro Shinosaki, Tatsuo Kobayashi, Kazuhiro Kimura, and Hidetake Kurihara
}

Shionogi Discovery Research Laboratories (TS, TK, KK), Shionogi and Company, Ltd., Toyonaka-City, Osaka, and Department of Anatomy (HK), Juntendo University School of Medicine, Bunkyo-ku, Tokyo, Japan

\begin{abstract}
SUMMARY: Dipeptidyl peptidase IV (DPPIV) is widely expressed in many tissues; however, its precise biological function is poorly understood. One of its possible physiologic roles is an involvement in the immune system, which plays a pivotal role in the pathogenesis of glomerulonephritis. The present study focused on the involvement of DPPIV in immune complex-mediated glomerulonephritis. Experimental nephritis was induced by anti-Thy-1.1 monoclonal antibody E30 using Wistar or F344 rats. The application of a new monoclonal antibody against DPPIV, F16, completely suppressed E30-induced proteinuria and mesangial proliferation in Wistar rats, whereas these preventive effects of F16 were not observed in F344 rats, which spontaneously lack DPPIV protein. Treatment with F16 inhibited glomerular deposition of complement C3 and complement C4 after the binding of E30 to the mesangial cell surface. Because the preventive effect of F16 was attributable to suppression of the complement cascade, we examined its influences on complement-dependent mesangial cell lysis in vitro. We discovered that the complement cascade was markedly inactivated in F16-treated Wistar rat serum but not in F16-treated F344 rats. These results indicate that DPPIV may play a somewhat crucial role in regulating the complement cascade and that inhibition of DPPIV may serve as a new target for preventing complement-dependent tissue injury. (Lab Invest 2002, 82:505-513).
\end{abstract}

$D$ ipeptidyl peptidase IV (DPPIV) is a serine protease and cleaves $\mathrm{N}$-terminal dipeptides of X-Ala or X-Pro from polypeptides and proteins (De Meester et al, 1999). This enzyme is widely distributed in a variety of tissues, including kidney, liver, small intestine, salivary gland, and serum (Duke-Cohan et al, 1995; Hopsu-Havu and Glenner, 1966; Oya et al, 1972; Svensson et al, 1978). In kidney tissue, DPPIV is abundant in the proximal tubular membrane, Fx1A, and the glomerular epithelial cell membrane. Fx1A includes nephritogenic antigens, because the antibody against the fraction induces passive Heymann nephritis (Feenstra et al, 1975; Heymann et al, 1959). An intraperitoneal injection of polyclonal antibodies against DPPIV also induces acute and massive proteinuria (Natori et al, 1986). Based on these results, DPPIV was suggested to be one of the major antigens responsible for passive Heymann nephritis. Subsequently, however, DPPIV was found to be irrelevant to the induction of passive Heymann nephritis (Natori et al, 1989). In fact, the administration of a monoclonal antibody against DPPIV caused proteinuria only in animals given complete Freund's adjuvant (Mendrick and Rennke, 1988). Thus, the role of DPPIV in renal function remains unknown.

DPPIV/CD26 is expressed on the cell surface of $\mathrm{CD}^{+} \mathrm{T}$ lymphocytes as well as in B cells and natural killer cells (Buhling et al, 1994, 1995; Morimoto et al, 1989). DPPIV activates T lymphocytes through stimu-

Received January 7, 2002.

Address reprint requests to: Toshihiro Shinosaki, Shionogi Research Laboratories, Shionogi and Company, Ltd., 3-1-1 Futaba-Cho, Toyonaka-City, Osaka 561-0825, Japan. E-mail: toshibiro.shinosaki@shionogi.co.jp lation of the T-cell receptor and enhances chemotactic migration of T cells (Iwata et al, 1999; Morimoto and Schlossman, 1998). High numbers of CD26 ${ }^{+}$cells are found at inflammation sites (Mizokami et al, 1996). Inhibitors for DPPIV suppress the secretion of various cytokines, such as IL-2, IL-10, IL-12, and IFN- $\gamma$, and induce the immunosuppressive cytokine TGF- $\beta 1$ (Reinhold et al, 1993, 1997; Steinbrecher et al, 2001). These findings strongly suggest that DPPIV may take part in immune responses. In connection with this, it is known that glomerulonephritis is triggered or aggravated by the immune response. It is then possible that suppression of DPPIV activity may alleviate the development of immune complex-mediated glomerulonephritis. The present study was undertaken to examine this possibility.

To address the above-mentioned question, we first prepared F16, a new monoclonal antibody against DPPIV, and then examined whether F16 could inhibit the development of immune complex-mediated glomerulonephritis. Immune complex-mediated glomerulonephritis (Thy-1.1 nephritis) can be induced experimentally by a single injection of a monoclonal antibody (clone E30) against mesangial cells (Shinosaki et al, 2002). Indeed, F16 treatment completely inhibited the development of Thy-1.1 nephritis induced by E30 in Wistar rats. We also used F344 rats, a spontaneously DPPIV-deficient strain that is useful for functional analysis on DPPIV activity in vivo (Tiruppathi et al, 1990; Watanabe et al, 1987). This inhibition of Thy-1.1 nephritis by F16 was not reproduced in F344 rats. Unexpectedly, however, our in vitro studies indicated that this inhibitory effect on nephritis was not a result of a direct action of F16 on DPPIV. Instead, 
inhibition of nephritis seems to be a result of suppression of a systemic complement cascade, which is induced by some as yet unknown factor(s) that is presumably produced by binding of F16 to DPPIV. Whatever the underlying mechanisms, DPPIV may be involved in regulation of the complement cascade.

There is little doubt that the complement system plays a pivotal role in glomerular injury or tubulointerstitial lesion, because complement activation results in immune tissue injury through formation of a membrane attack complex and generation of chemotactic factors (Couser et al, 1992; Hebert et al, 1992; Morita et al, 1997). The present study is the first demonstration of the implication of DPPIV in the complement cascade. The results suggest that DPPIV may be a new therapeutic target for complement-dependent renal injury.

\section{Results}

\section{Characterization of F16 Monoclonal Antibody}

F16 mouse monoclonal antibody was selected by screening of monoclonal antibodies against rat glomerular fractions. Immunofluorescence with F16 showed intense labeling on the brush-border membrane of proximal tubular epithelial cells and weak signals on the glomerular epithelial cell membranes in Wistar rats (Fig. 1A). In contrast, immunostaining for F16 was totally negative in the kidney sections from
F344 rats. F16 recognized two bands (113- and 125$\mathrm{kDa}$ polypeptides) in both the glomerular and brushborder membrane (Fx1A) fractions. Based on the molecular weight, localization, and lack of antigen in F344 rats, we predicted that the antigen might be DPPIV. We then prepared the Fx1A fraction from brush-border membranes of Wistar rats. The membrane fractions were fractionated into about 50 samples with sodium-density gradient. Figure 1B shows the relationship between the enzymatic activity of DPPIV and the amount of antigen for F16 in each fractionated sample. The enzymatic activity of DPPIV increased in fraction nos. 29-36, peaking at no. 31. As shown in the upper panel, immunoblotting for F16 showed that the antigen for F16 abounded in fraction nos. 30-32, corresponding to the peak of enzymatic activity of DPPIV. Thus, the antigen for F16 is likely to be DPPIV. We then cloned the rat DPPIV gene by a PCR-cloning technique based on the sequence in a previous report (Ogata et al, 1989) and produced rat DPPIV protein by in vitro transcription and translation in reticulocyte lysate to examine whether the gene product could be detected by F16. As shown in Figure 1C, F16 recognized the protein from reticulocyte lysate mixed with amplified sense cDNA of rat DPPIV (lane 1). In contrast, no reticulocyte lysate translated with antisense cDNA was detected by F16 (lane 2). Taken together, we concluded that F16 is a monoclonal antibody specific for rat DPPIV.

\section{Effects of F16 on Experimentally Induced Nephritis (In Vivo Study)}

Previous studies have demonstrated that E30 recognizes rat mesangial Thy-1.1 antigen and that intravenous injection of E30 induces complement-dependent mesangial cell injury followed by a rapid proliferation of mesangial cells. Figure 2 shows the changes of urinary protein excretion in Wistar or F344 rats treated with E30. Wistar rats treated with E30 alone showed massive proteinuria. Simultaneous injection of F16

(C)

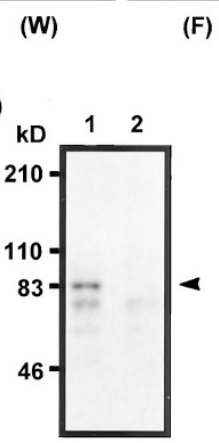

(F)

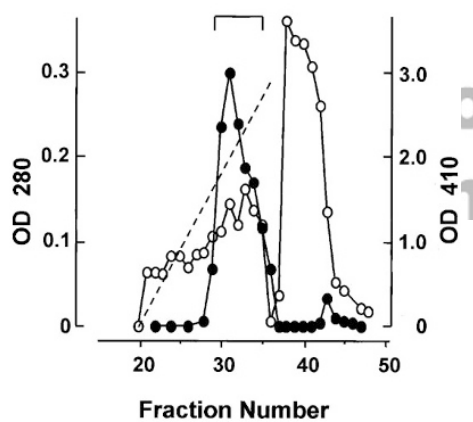

Figure 1.

Characterization of F16 monoclonal antibody. A, Immunofluorescence of F16 monoclonal antibody in renal tissue from Wistar (W) and F344 (F) rats. F16 recognized its antigen expressed in glomerular epithelial cells and proximal tubules in Wistar rats, whereas no signal was detected in F344 rats. $G=$ Glomerulus; PT = Proximal tubule. B, Relationship between enzymatic activity of dipeptidyl peptidase IV (DPPIV) and the amount of F16-recognized protein in Fx1A fraction. Enzymatic activity of DPPIV corresponded to the amount of antigen for F16. Symbols are as follows: $(\bullet)$ absorbance at $410 \mathrm{~nm}$; $(\bigcirc)$ absorbance at $280 \mathrm{~nm}$. Dashed line indicates density-gradient of sodium chloride (0 to $0.3 \mathrm{M})$. C, In vitro transcription and translation in reticulocyte lysate. F16 detected rat DPPIV gene product obtained from reticulocyte lysate. The sense (lane 1) or antisense (lane 2) CDNA of rat DPPIV amplified by PCR was applied to the lysate.
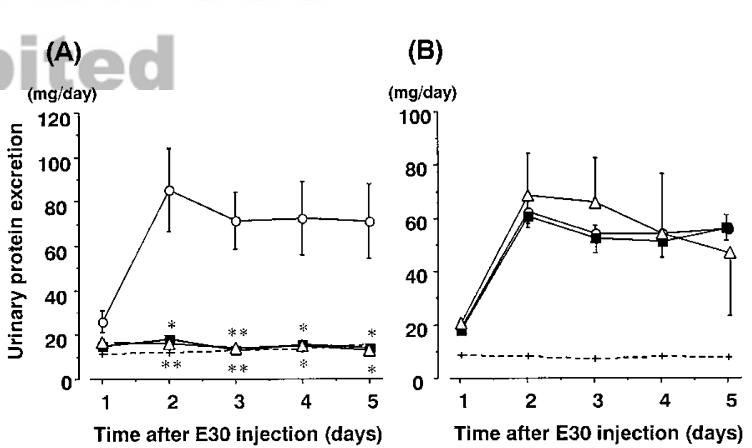

Figure 2.

Effects of F16 monoclonal antibody on E30 monoclonal antibody (E30)induced massive proteinuria in Wistar (A) and F344 (B) rats. Plots show the mean values and the bars and the standard errors. E30-induced massive proteinuria was completely inhibited by simultaneous injection of F16 in Wistar rats but not in F344 rats. Symbols are as follows: $(+)$ normal $(n=2) ;(\bigcirc) 100$ $\mu \mathrm{g}$ of $\mathrm{E} 30(n=3) ;(\square)$ E30 plus $300 \mu \mathrm{g}$ of $\mathrm{F} 16(n=3)$; and $(\Delta)$ E30 plus 1 $\mathrm{mg}$ of F16 $(n=3)$. ${ }^{*},{ }^{* *}$ : Significantly different from E30-treated value at $p<$ 0.05 and $p<0.01$, respectively. 
with E30 completely suppressed E30-induced proteinuria. The amount of protein excretion in rats treated with two monoclonal antibodies was the same as that in nontreated rats. The antiproteinuric effect observed by a single injection of F16 lasted throughout the experiment (Fig. 2A). In F344 rats, which lack DPPIV protein, E30 treatment also caused a significant increase in protein excretion. The amount of protein excretion after E30 injection was almost the same between Wistar and F344 rats. In contrast with Wistar rats, however, the inhibitory effect of F16 on the proteinuria induced by E30 was not observed in F344 rats (Fig. 2B). These results suggest that inhibition of E30-induced nephritis by F16 is mediated by DPPIV. This inhibitory effect of F16 was not specific to E30induced glomerulonephritis but was also observed in nephritis rats induced by another anti-Thy-1.1 monoclonal antibody, OX-7 (data not shown).

If the F16 treatment was started 1 hour before or immediately after E30 injection, massive proteinuria was not induced. The potency of F16 depended on the time of its administration after E30 injection. When F16 was given 30 minutes after E30 injection, its inhibitory effect was about $50 \%$ of that of simultaneous injection of both monoclonal antibodies (Fig. 3A). In our Thy-1.1 nephritis model, the number of proliferating cell nucleic antigen (PCNA) positive glomerular cells peaked on Day 5. More than $90 \%$ of PCNA-positive cells were identified as mesangial cells. We also investigated whether F16 could inhibit mesangial proliferation on Day 5 (Fig. 3B). Only a few PCNA-positive cells were noted in a glomerulus in normal rats (not shown). In rats treated with $\mathrm{E} 30$ alone, the number of PCNApositive glomerular cells increased to $38 \pm 2$ (counts/ single glomerulus). Pretreatment or simultaneous administration of $\mathrm{F} 16$ resulted in a marked decrease in the number of PCNA-positive cells. When F16 was

(A)
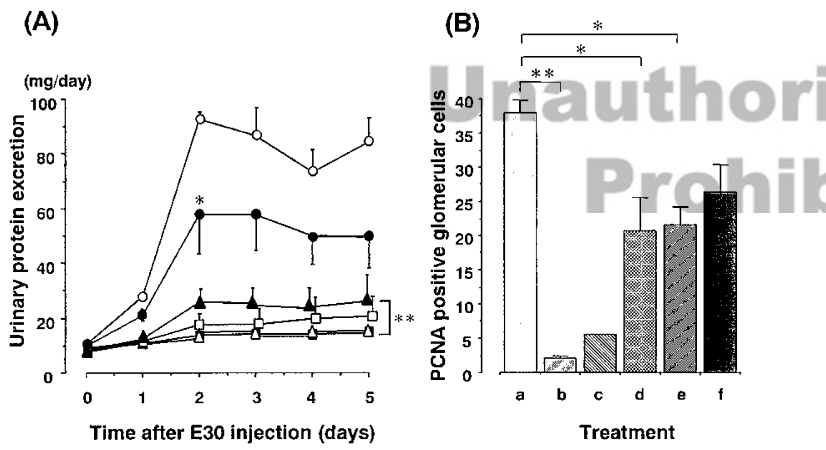

Figure 3.

Prophylactic and therapeutic effects of F16 monoclonal antibody on E30induced massive proteinuria (A) and cell proliferation (B) on Day 5 in Wistar rats. Plots and columns show the mean values and the bars and the standard errors. F16 $(300 \mu \mathrm{g})$ was intravenously administered. Treatment of F16 suppressed both proteinuria and mesangial proliferation. The potency of F16 depended on the injection time. Symbols are as follows: (O) E30 control (column a: $n=4$ ); ( $\square$ ) F16 was given 1 hour before E30 injection (column b: $n=3$ ); $(\Delta)$ F16 was given immediately after E30 injection (column c: $n=2$ ); ( $\square$ ) F16 was given 5 minutes after E30 injection (column d: $n=4$ ); $(\mathbf{\Delta})$ F16 was given 15 minutes after E30 injection (column e: $n=4$ ); and (O) F16 was given 30 minutes after E30 injection (column f: $n=4$ ). ${ }^{*},{ }^{* *}$ : Significantly different from E30-treated value at $p<0.05$ and $p<0.01$, respectively. given 5 or 15 minutes after E30 injection, its suppressive effect on cell proliferation was weaker. When F16 was administered 30 minutes after E30 injection, there was no statistically significant difference in the number of PCNA-positive cells compared with the E30-treated group. Thus, the inhibitory effect of F16 on mesangial cell proliferation induced by E30 seems to parallel the degree of massive proteinuria.

Because Thy-1.1 nephritis is known to require activation of the complement system in its initiation process, we investigated the deposition of complement C3 (C3) in the glomerular region after the treatment of monoclonal antibodies by immunofluorescence (Fig. 4). In Wistar rats treated with E30 alone, the deposition of $\mathrm{C} 3$ became conspicuous in the mesangial region 30 minutes later. The deposition of C3 was also blocked by F16 applied immediately after E30 injection. In nontreated rats or rats treated with F16 alone, signals for C3 were not detected in glomeruli. Therefore, F16 seemed to affect activation of the complement cascade. Next we examined the glomerular deposition of complement C4 (C4), which is primarily activated in the classical pathway, to clarify whether F16-induced prevention of C3 deposition was attributable to suppression of C4 activation (Fig. 5). C4 deposition was observed in rat glomeruli treated with E30 alone. The deposition in the mesangial region was inhibited by F16 treatment.

\section{Effects of F16 on Complement-Dependent Mesangial Cell Lysis (In Vitro Study)}

The preceding in vivo observations were complemented by in vitro studies to examine the influences of F16 on complement-dependent cell lysis. The cultured mesangial cell lysis assay used here has been shown to be a reliable method for evaluating complementdependent cell injury (Nangaku et al, 1996, 1997; Yamada et al, 2001). To induce cell lysis, addition of
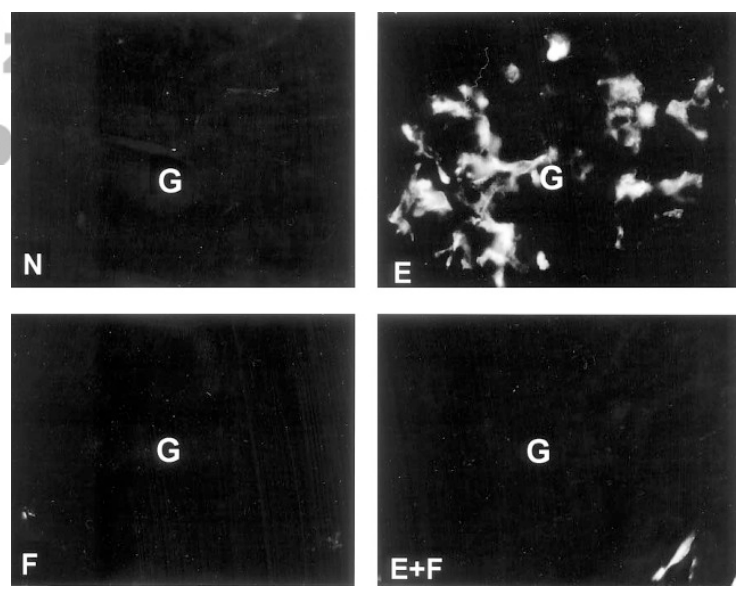

Figure 4.

Immunofluorescence of complement C3 (C3) in rat glomeruli 30 minutes after the treatment of monoclonal antibodies. Treatment of E30 resulted in C3 deposition in the glomerular region 30 minutes later. Simultaneous injection of F16 with $\mathrm{E} 30$ prevented the deposition. $\mathrm{N}=$ Normal without monoclonal antibody; $E=E 30$-treated alone; $F=F 16$-treated alone; $E+F=$ Simultaneous injection of $\mathrm{E} 30$ with $\mathrm{F} 16 ; \mathrm{G}=$ Glomerulus. 

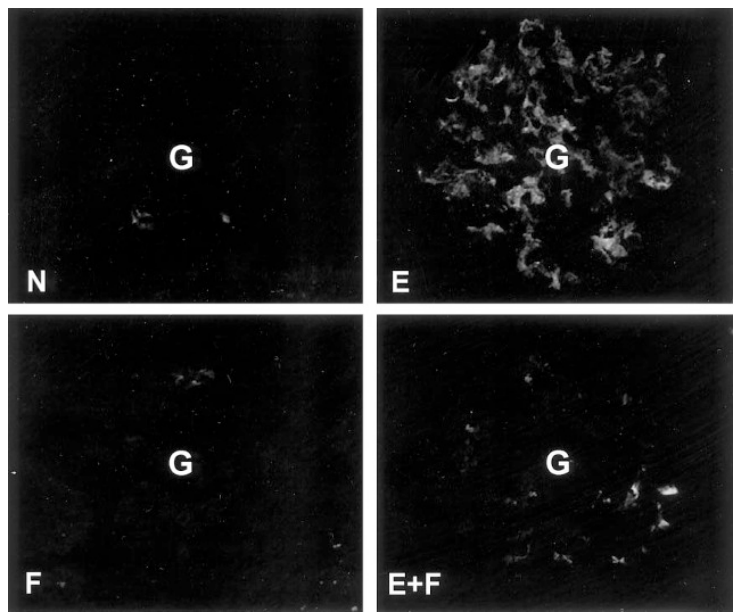

Figure 5.

Immunofluorescence of complement C4 (C4) in rat glomeruli 30 minutes after the treatment of monoclonal antibodies. Treatment of F16 attenuated E30induced glomerular C4 deposition remarkably. Prevention of C4 activation contributes to F16-induced inhibition of the complement cascade. $\mathrm{N}=$ Normal without monoclonal antibody; $\mathrm{E}=\mathrm{E} 30$-treated alone; $\mathrm{F}=\mathrm{F} 16$-treated alone; $\mathrm{E}+\mathrm{F}=$ Simultaneous injection of $\mathrm{E} 30$ with $\mathrm{F} 16 ; \mathrm{G}=$ Glomerulus.

both anti-Thy-1.1 antibody and rat serum as a complement source to cultured mesangial cells is required. Three anti-Thy-1.1 antibodies (E30, OX-7, and antithymocyte serum) were available in this assay system. We decided to use OX-7 instead of E30 because of its strong potency on cell lysis (not shown). The direct effect of F16 on mesangial cell lysis was evaluated by adding F16 to normal rat serum. Under normal conditions without anti-Thy-1.1 antibody, the increment in the concentration of lactate dehydrogenase (LDH) during 15 minutes was 5 to $10 \mathrm{mU} / \mathrm{ml}$. The addition of OX-7 markedly increases the LDH concentration, indicating that OX-7 induces complement-dependent mesangial cell lysis (Table 1). Surprisingly, however, this cell lysis was not affected by F16 at $30 \mu \mathrm{g} / \mathrm{ml}$. F16 treatment at $100 \mu \mathrm{g} / \mathrm{ml}$ tended to reduce the increase in LDH. However, there was no indication that complement-dependent mesangial cell lysis induced by $\mathrm{OX}-7$ plus normal rat serum can be prevented by $100 \mu \mathrm{g} / \mathrm{ml}$ of $\mathrm{F} 16$. This suggests that F16 cannot directly inhibit the complement cascade.

Table 1. Effect of F16 Monoclonal Antibody on Complement-Dependent Mesangial Cell Lysis Induced by anti-Thy-1.1 Antibody, 0X-7

\begin{tabular}{|c|c|c|}
\hline Treatment & $\mathrm{N}$ & $\begin{array}{l}\text { Increase in the } \\
\text { concentration } \\
\text { of LDH in } \\
\text { cultured medium } \\
(\mathrm{mU} / \mathrm{ml})\end{array}$ \\
\hline 0X-7 + serum & 4 & $82.0 \pm 3.1$ \\
\hline $0 \mathrm{X}-7+$ serum $+\mathrm{F} 16(30 \mu \mathrm{g} / \mathrm{ml})$ & 4 & $81.9 \pm 2.6$ \\
\hline $0 X-7+$ serum + F16 $(100 \mu \mathrm{g} / \mathrm{ml})$ & 4 & $73.8 \pm 3.0$ \\
\hline
\end{tabular}

LDH, lactate dehydrogenase.

${ }^{a}$ Data represent as the mean and standard error. The mean value was calculated from quadruplicate for each group.
This puzzling discrepancy in the effect of F16 might be attributed to differences in the procedure of its application. F16 was intravenously applied in in vivo studies, whereas F16 was mixed with normal rat serum immediately before applying to the cultured mesangial cells in in vitro studies. To make the procedure of F16 application in in vitro studies comparable to that in in vivo studies, we injected F16 (300 $\mu \mathrm{g} / \mathrm{rat})$ to Wistar or F344 rats. Then, serum samples were obtained 1 hour later to investigate cell lysis activity. Under this condition, the cell lysis activity of F16treated Wistar rat serum decreased significantly (Fig. 6), indicating F16-induced reduction of the potency for activating the complement cascade. In contrast, the serum similarly prepared from F344 rats after F16 injection showed no reduction in cell lysis activity. C3 deposition in mesangial cells corresponded to the degree of cell lysis. Intense staining for C3 was observed in mesangial cells when normal rat serum was added to the cultured cells (Fig. 7). The intensity of C3 staining was faint in the F16-treated Wistar rat serum-applied group. On the contrary, when added with F16-treated F344 rat serum to mesangial cells, the signal for C3 was clearly detected. These results indicate that F16 is essential for the inhibition of

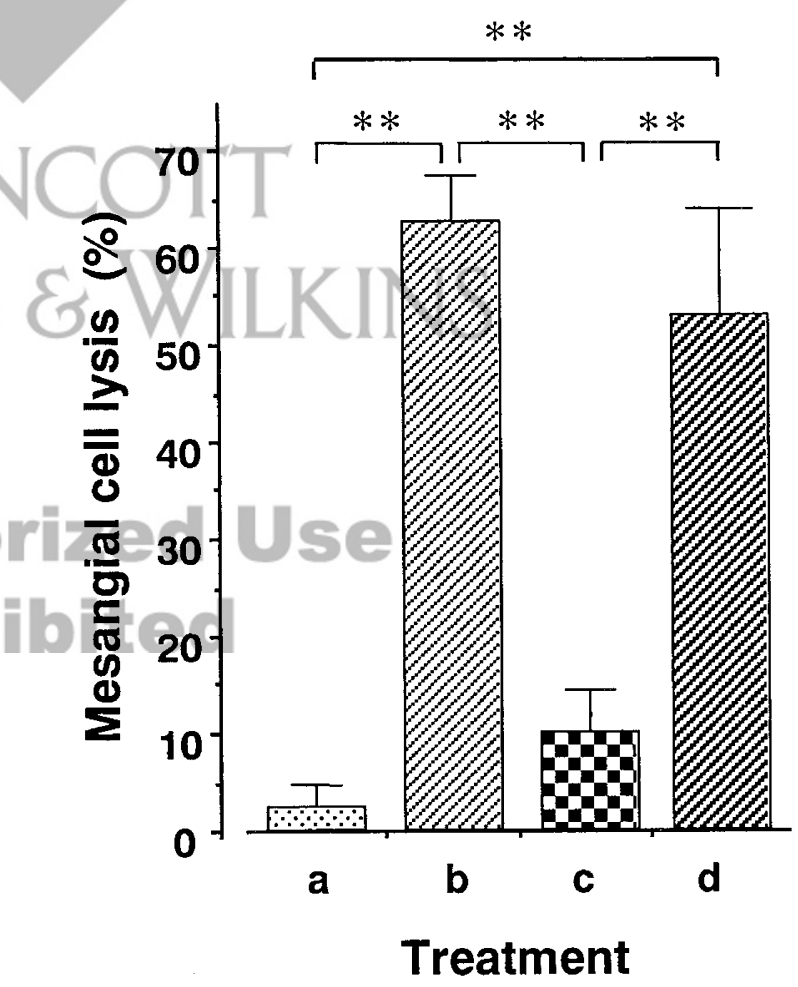

Figure 6.

Differences of cell lysis activities between F16-treated serum obtained from Wistar and F344 rats. Columns show the mean values and the bars and the standard errors $(n=4)$. Serum samples from Wistar or F344 rats were obtained 1 hour after intravenous injection of F16 at a dose of $300 \mu \mathrm{g} / \mathrm{rat}$. F16 treatment remarkably reduced cell lysis activity of Wistar rat serum, but the activity of F344 rat serum was unchanged by F16. a, normal Wistar rat serum only (without OX-7); b, OX-7 plus normal Wistar rat serum; c, OX-7 plus F16-treated Wistar rat serum; d, OX-7 plus F16-treated F344 rat serum. Asterisks indicate that the difference is statistically significant $(p<0.01)$. 

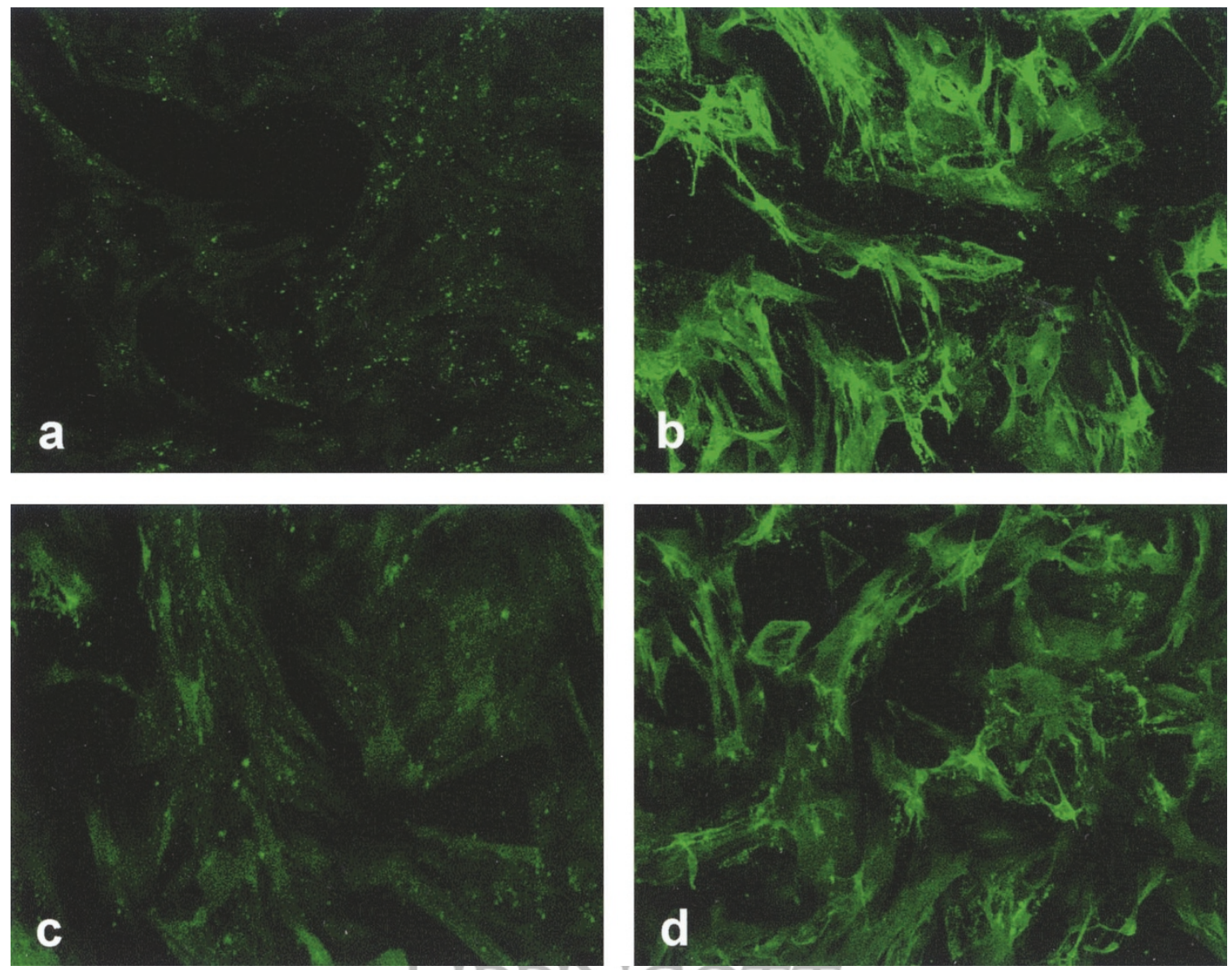

Figure 7.
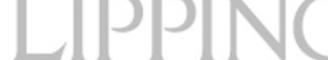

Immunofluorescent staining for $\mathrm{C} 3$ in cultured mesangial cells. a, Normal mesangial cells without complement attack showed no staining with anti-C3 antibody. b, Mesangial cells subjected to lytic complement attack showed conspicuous signal for C3. The strong sighal was attenuated markedly by F16 in Wistar rats (c), whereas C3 deposition was unchanged by F16 in Fisher rats (d). a, normal Wistar rat serum only (without OX-7); b, OX-7 plus normal Wistar rat serum; c, 0X-7 plus F16-treated Wistar rat serum; d, OX-7 plus F16-treated F344 rat serum.

nephritis, although this inhibition may not be a direct consequence of F16.

\section{Discussion}

The main outcome of the present study is that F16, a new monoclonal antibody against DPPIV, completely inhibited the induction of Thy-1.1 nephritis in Wistar rats. This effect was not observed in F344 rats that lack DPPIV protein. Thus, the binding of F16 to DPPIV seems to be essential for inhibiting Thy-1.1 nephritis.

Thy-1.1 nephritis represents immune complex-mediated glomerulonephritis. Glomerular lesions in nephritis include mesangiolysis and subsequent mesangial cell proliferation. The binding of anti-Thy- 1.1 antibodies to their antigens of mesangial cells activates the complement cascade to induce mesangial cell lysis. Mesangial cell lysis occurs sporadically as early as 30 minutes after E30 injection (not shown). Thus, activation of the complement cascade is the initial process of nephritis. Consistent with this notion, depletion of complement components by pretreatment with cobra venom is known to prevent mesangial cell lysis (Yamamoto and Wilson, 1987).
F16 treatment failed to suppress nephritis when administered 2 hours after E30 injection (not shown). -Therefore, we reasoned that inhibition of nephritis by F16 requires suppression of the initial process, that is, activation of the complement cascade. When F16 and E30 were administered simultaneously, deposition of the C3 component was not detected in glomeruli. At present, three complement activation pathways are known: the classical, alternative, and mannose binding proteinassociated pathways. Although the initial triggers differ, all of the pathways eventually activate the C3 component, thereby forming a membrane attack complex. Our findings that treatment of $\mathrm{F} 16$ also inhibits $\mathrm{C} 4$ deposition in vivo indicate that suppression of complement cascade by F16 is attributable, at least in part, to prevention of the classical pathway, because activation of C4 is not required in the alternative pathway. This, however, does not exclude the possible involvement of F16 in the alternative pathway.

There is little doubt that binding of F16 to DPPIV is a prerequisite for inhibiting Thy-1.1 nephritis. However, the precise mechanism underlying this inhibition remains uncertain. Cultured mesangial cell lysis induced by the anti-Thy-1.1 antibody OX-7 was not 
prevented by high concentrations (up to $100 \mu \mathrm{g} / \mathrm{ml}$ ) of F16 applied to cultures. Therefore, F16 does not seem to inhibit nephritis by direct action. On the other hand, the application of serum obtained from Wistar rats 1 hour after treatment with F16 could prevent OX-7induced mesangial cell lysis, when applied to the cultures. Again, the serum obtained from F344 rats lacking DPPIV protein failed to protect OX-7-induced mesangial cell lysis even after treatment with $\mathrm{F} 16$. This implies that the binding of F16 to DPPIV may produce some as yet unidentified factor(s) that can lead to prevention of mesangial cell lysis, thereby contributing to inhibition of Thy-1.1 nephritis. The serum obtained from Wistar rats pretreated with F16 was also effective in protecting mesangial cell lysis even when F16 was injected after bilateral occlusion of the renal artery (not shown). This suggests that inhibition of nephritis does not require a binding of F16 to DPPIV in the kidney. Rather, binding of F16 to serum DPPIV seems to be essential for inactivation of the systemic complement cascade.

IgG has been reported to regulate the classical complement pathway, because IgG treatment prevents complement-dependent hyperacute rejection (Magee et al, 1995). However, the classical pathway can be inhibited by $\operatorname{lgG}$ only at high doses $(2 \mathrm{~g} / \mathrm{kg})$. In contrast, F16 could suppress the complement cascade at low doses (1 to $3 \mathrm{mg} / \mathrm{kg}$ ). How is the systemic complement cascade inactivated by F16? Two possible mechanisms may be considered: depletion of complement components and activation of complement regulatory proteins. It takes more than several hours to deplete complement component (Brandt et al, 1996; Yamamoto and Wilson, 1987). Therefore, this mechanism cannot account for the rapid inactivation of systemic complement cascade by F16. Thus, it is likely that F16 may activate complement regulatory proteins such as $\mathrm{C} 1$ esterase inhibitor and Factor I (Johnson, 1997), thereby leading to suppression of the complement cascade. Previous studies have demonstrated the potential usage of complement regulatory proteins as a curative against complement-dependent tissue injury (Higgins et al, 1997; Weisman et al, 1990). In nephrotoxic serum nephritis, continuous complement inhibition at the C3 convertase step by overexpression of complement receptor 1-related gene/protein y has been shown to be effective for protecting against renal injury (Quigg et al, 1998). DPPIV may not directly participate in the systemic complement cascade. However, DPPIV may regulate the complement cascade via involvement in the denaturalization processes of regulatory proteins. If so, binding of F16 to DPPIV may induce alterations in the properties of regulatory proteins, which, in turn, suppress the systemic complement cascade, consistent with our findings of an indirect suppressive effect of F16.

\section{Materials and Methods}

\section{Animals}

Six-week-old male Wistar rats were purchased from Japan SLC (Shizuoka, Japan). Male F344 (6 week old) rats were from Charles River Japan (Kanagawa, Japan). Animals were given free access to standard solid chow (CA-1; CLEA Japan, Shiga, Japan) and tap water. All animal experiments complied with the "Principles of the Animal Care and Use Committee of Shionogi."

\section{Characterization of F16 Monoc/onal Antibody}

Preparation of Monoclonal Antibodies. The isolated glomeruli were prepared as previously described (Kurihara et al, 1998). Briefly, Wistar rat glomeruli were isolated by a standard sieving technique at $4^{\circ} \mathrm{C}$ in the presence of protease inhibitors. Glomerular fractions were collected by centrifugation and washed with PBS containing protease inhibitors. Monoclonal antibodies were prepared as previously reported (Kurihara et al, 1998). Female BALB/c mice were immunized with isolated glomeruli. The immunization was performed with intraperitoneal injections of a mixture of isolated glomeruli with complete Freund's adjuvant (Difco Laboratories, Detroit, Michigan). The mice were then given two booster injections of the mixture of isolated glomeruli and incomplete Freund's adjuvant at an interval of 2 weeks. After 2 weeks, the same volume of glomeruli without adjuvant was injected intraperitoneally, and the spleen was removed 4 days later. Spleen cells of immunized mice were fused with mice myeloma cells $(\mathrm{P} 3 \times 63 \mathrm{Ag} 8.653)$ at a $3 / 1$ ratio of splenocytes to myeloma cells. Antibody screening was performed on rat kidney frozen sections by indirect immunofluorescence technique. The IgG fraction was purified from ascites fluid by protein G-Sepharose (Pharmacia, Uppsala, Sweden) affinity chromatography according to the manufacturer's instructions. Localization of the Antigen for F16 in Kidney Tissue from Wistar or F344 Rats. Wistar or F344 rat kidneys were perfused with $4 \%$ paraformaldehyde fixative buffered with $0.1 \mathrm{M}$ phosphate buffer $(\mathrm{pH} 7.4)$ and immersed in the same fixative for 1 hour at room temperature. After fixation, the tissue samples were rinsed successively in PBS containing $10 \%, 15 \%$, and $20 \%$ sucrose (4 hours each). Cryosections (thickness, 2 to $4 \mu \mathrm{m}$ ) were cut using a Tissue-Tek-II Microtome/ Cryostat (Miles Scientific, Naperville, Illinois) and then mounted on gelatin-coated glass slides and rinsed three times in PBS (10 minutes each). The sections were processed for staining with the F16 monoclonal antibody. The sections were incubated for 2 hours at room temperature with mouse monoclonal antibody F16 (diluted 1:100 of ascites fluid). Next, the sections were incubated with FITC-labeled sheep anti-mouse immunoglobulin (Amersham, Arlington Heights, Illinois) diluted 1:100 for 1 hour at room temperature. In control experiments, incubation with the primary antibody was omitted. All sections were examined using an FX-S RFL fluorescence microscope (Nikon, Tokyo, Japan).

Purification of DPPIV as F16 Antigen. Renal tubular fraction, Fx1A, was prepared from Wistar rats as described previously (Natori et al, 1986). Solubilized and dialyzed membrane fractions were applied to a 
DEAE-Sephacel column (Pharmacia). The column was washed with $20 \mathrm{~mm}$ Tris- $\mathrm{HCl}, \mathrm{pH}$ 7.6, and a linear gradient was made with $6 \mathrm{ml}$ of the same buffer in the mixing vessel and an equal volume of $20 \mathrm{~mm}$ Tris- $\mathrm{HCl}$, $\mathrm{pH}$ 7.6, containing $0.3 \mathrm{M} \mathrm{NaCl}$. Further elution was performed with $3 \mathrm{ml}$ of $1 \mathrm{M} \mathrm{NaCl}$. The proteins were measured by absorbance at $280 \mathrm{~nm}$, and the DPPIV content was measured at $410 \mathrm{~nm}$ on the basis of enzyme activity using photometry as previously described (Natori et al, 1987). Aliquots of the fractions were processed for immunoblot analysis with F16.

Western Blotting Analysis with F16. Tissue samples were solubilized in PBS containing protease inhibitors, $1 \%$ SDS, and 5 mм EDTA; samples were electrophoresed ( $50 \mu \mathrm{g}$ protein/lane) on $7.5 \%$ polyacrylamide gel and transferred to a nitrocellulose membrane. Blots were incubated with $\mathrm{F} 16$ and then with alkaline phosphatase (ALP)-conjugated goat anti-mouse IgG and detected using the ALP Western Blotting Detection System (BioRad, Laboratories, Tokyo, Japan).

In Vitro Transcription and Translation of DPPIV Protein in Reticulocyte Lysate. The single-strand CDNAencoding rat DPPIV was obtained from rat kidney poly $\mathrm{A}^{+}$RNA (Clontech, Palo Alto, California) by RT-PCR. Briefly, the cDNA was synthesized using Super Script reverse transcriptase (GIBCO BRL, Rockville, Maryland) and random hexamer. The primers for PCR were constructed based on the sequence of rat DPPIV (Ogata et al, 1989). The PCR was performed with the sense primer 5'-AGAGTTCAGTTTCAAGGAGCCG-3' and the antisense primer 5'-TGAGGACAAGTGTGCTCTTGAG-3'. The PCR reaction was performed under the following conditions: $94^{\circ} \mathrm{C}$ for 2 minutes and then 35 cycles at $94^{\circ} \mathrm{C}$ for 1 minute, $60^{\circ} \mathrm{C}$ for 1 minute, and $72^{\circ} \mathrm{C}$ for 3 minutes. The amplified product was cloned into the pT7Blue (R) vector (Novagen, Madison, Wisconsin). In vitro transcription and translation of DPPIV protein were performed in reticulocyte lysate using the TnT Coupled Reticulocyte Lysate Systems (Promega, Madison, Wisconsin) following the manufacturer's instructions. The resultant protein was processed for immunoblotting with F16.

\section{Effects of F16 on Experimentally Induced Nephritis (In Vivo Study)}

Before the experiment, Wistar or F344 rats were housed in stainless metabolic cages for acclimation for 2 days. Individuals that did not become accustomed to the cage were excluded from the experiment. Thy-1.1 nephritis was induced by a single intravenous injection of E30 (100 $\mu \mathrm{g} / \mathrm{rat})$. The F16 solution in saline was administered to rats from the caudal vein at doses of 300 or $1000 \mu \mathrm{g} / 0.5 \mathrm{ml} / \mathrm{rat}$ immediately after E30 injection $(n=3)$. The animals were housed in metabolic cages for 5 days with free access to food and water. Twenty-four hour urine samples were collected every day, and the amount of urinary protein excretion was measured with Micro TP-Test Wako (Wako Pure Chemical Industries, Osaka, Japan).
Because F16 proved to suppress E30-induced massive proteinuria in Wistar rats, we next investigated the therapeutic effect of F16 on Thy-1.1 nephritis. Seven-week-old male Wistar rats were used. Induction of glomerulonephritis was performed as stated above. The animals were divided into six groups: Group a, E30-treated alone $(n=4)$; Group b, E30 plus F16 (1 hour before E30 injection, $n=3$ ); Group c, E30 plus F16 (immediately after E30 injection, $n=2$ ); Group d, E30 plus F16 (5 minutes after E30 injection, $n=4)$; Group e, E30 plus F16 (15 minutes after E30 injection, $n=4$ ); and Group f, E30 plus F16 (30 minutes after E30 injection, $n=4$ ). F16 (300 $\mu \mathrm{g} / \mathrm{rat}$ ) in saline was given to the animals before or after E30 injection for each group. The therapeutic effects of F16 on nephritis were evaluated based on urinary protein excretion and mesangial cell proliferation. On Day 5, the left kidney of each animal was quickly removed under anesthesia with sodium pentobarbital. The kidney tissue sample was fixed in methacarn solution ( $\mathrm{MeOH}: \mathrm{CHCl}_{3}: \mathrm{AcOH}=6: 3: 1$ ) and embedded in paraffin. Next, 4- $\mu \mathrm{m}$-thick fixed sections were placed onto slides and processed for immunostaining of PCNA.

PCNA staining was performed as described below at room temperature. After blocking with normal horse serum for 20 minutes, sections were incubated with monoclonal mouse anti-rat PCNA antibody (Novocastra, Newcastle, United Kingdom) diluted 1:100 with PBS for 1 hour and washed with PBS. The sections were incubated with biotinylated horse anti-mouse IgG antibody for 30 minutes, washed with PBS, and then placed in methanol containing $0.3 \% \mathrm{H}_{2} \mathrm{O}_{2}$ for 20 minutes to neutralize endogenous peroxidase. The sections were washed thoroughly with PBS and visualized by reaction with avidin-biotin peroxidase using the Vectastain $A B C$ kit (Vector, Burlingame, California). The sections were then incubated with diaminobenzidine solution for several minutes, and the reaction was terminated. Expression of PCNA was quantified by counting the number of PCNA-positive cells per glomerular section. The individual number of glomerular PCNA-positive cells was determined by calculating the mean value from more than 30 glomeruli per single section.

Immunofluorescence for C3 and C4 in Rat Glomeruli. To investigate whether F16 treatment affected the complement cascade, deposition of $\mathrm{C} 3$ and $\mathrm{C} 4$ in the glomerular region was studied using immunofluorescence in Wistar rats. At 30 minutes after injection of E30 $(100 \mu \mathrm{g} / \mathrm{rat}), \mathrm{F} 16(1 \mathrm{mg} / \mathrm{rat})$, or both, the kidney tissues were removed quickly and processed for detection of $\mathrm{C} 3$ and $\mathrm{C} 4$. The $\mathrm{C} 3$ on the kidney sections was detected by using FITC-conjugated anti-rat C3 antibody (Cappel-Organon Teknika, Durham, North Carolina), whereas immunohistochemistry of $\mathrm{C} 4$ was performed with FITC-conjugated anti-human C4 antibody (Chemicon, Temecula, California).

\section{Effect of F16 on Complement-Dependent Mesangial Cell Lysis (In Vitro Study)}

Mesangial Cell Culture. Glomeruli from 4- to 5-week-old male Wistar rats were isolated by a stan- 
dard sieving method as stated above. Glomerular fractions were collected by centrifugation and washed with PBS. The isolated glomeruli were plated on a 6-well tissue culture plate at a density of 1000 glomeruli per well and cultured with RPMI-1640 supplemented with $20 \%$ fetal bovine serum and a $1 \%$ solution mixture containing penicillin, streptomycin, and amphotericin $\mathrm{B}$ at $37^{\circ} \mathrm{C}$ under $5 \% \mathrm{CO}_{2}$. Mesangial cells between passages 9 and 15 were used for the cell lysis assay.

Complement-Mediated Mesangial Cell Lysis Assay. Mesangial cells were placed in 12-well tissue culture plates and cultivated until they were almost confluent (more than 90\%). Cell lysis assay was performed based on the procedure of Nangaku et al (1997). Briefly, the mesangial cells were washed two times with HBSS (Gibco BRL) and sensitized with the antiThy 1.1 monoclonal antibody OX-7 (150 $\mu \mathrm{g} / \mathrm{ml})$ for 30 minutes at $37^{\circ} \mathrm{C}$. OX-7 was purified from a hybridoma cell line purchased from the European Collection of Animal Cell Cultures (Porton Down, Salisbury, United Kingdom). After further washing with HBSS for two times, the cells were incubated with $800 \mu$ l of $20 \%$ rat serum diluted with HBSS for 15 minutes at $37^{\circ} \mathrm{C}$. Cell lysis was quantitated by the amount of LDH that had leaked into the cultured medium during the incubation period. Fifty-microliter samples of the cultured medium were obtained before and immediately after the incubation. The mesangial cells were subsequently processed for the measurement of intracellular LDH or immunocytochemical study for C3. For the determination of intracellular LDH, the cells were lysed with 800 $\mu \mathrm{l}$ of $5 \%$ Triton $\mathrm{X}-100$, and the complement-mediated cell lysis percentage was calculated. The enzymatic activity of LDH was measured with LDH-FA Test Wako (Wako Pure Chemical Industries). To detect the deposition of $\mathrm{C} 3$, the cells were fixed with 1:1 acetonemethanol for 10 minutes and stained with FITClabeled anti-rat C3 antibody (diluted 1:100 with PBS; Cappel-Organon Teknika). Immunofluorescent staining for C3 was observed with a laser scanning microscope (Olympus FLUOVIEW, Tokyo, Japan).

\section{Statistics}

Data are expressed as the mean and standard error. The significance of the difference from each value was calculated by Tukey's method (Wallenstein et al, 1980). Statistical significance was set up at $p<0.05$.

\section{References}

Brandt J, Pippin J, Schulze M, Hansch GM, Alpers CE, Johnson RJ, Gordon K, and Couser WG (1996). Role of the complement membrane attack complex (C5b-9) in mediating experimental mesangioproliferative glomerulonephritis. Kidney Int 49:335-343.

Buhling F, Junker U, Reinhold D, Neubert K, Jager L, and Ansorge S (1995). Functional role of CD26 on human B lymphocytes. Immunol Lett 45:47-51.

Buhling F, Kunz D, Reinhold D, Ulmer AJ, Ernst M, Flad HD, and Ansorge S (1994). Expression and functional role of dipeptidyl peptidase IV (CD26) on human natural killer cells. Nat Immun 13:270-279.

Couser WG, Schulze M, and Pruchno CJ (1992). Role of C5b-9 in experimental membranous nephropathy. Nephrol Dial Transplant 7:S25-S31.

De Meester I, Korom S, Van Damme J, and Scharpe S (1999). CD26, let it cut or cut it down. Immunol Today 20:367-375.

Duke-Cohan JS, Morimoto C, Rocker JA, and Schlossman SF (1995). A novel form of dipeptidylpeptidase IV found in human serum: Isolation, characterization, and comparison with T lymphocyte membrane dipeptidylpeptidase IV (CD26). J Biol Chem 270:14107-14114.

Feenstra K, Lee RVD, Greben HA, Arends A, and Hoedemaeker PHJ (1975). Experimental glomerulonephritis in the rat induced by antibodies directed against tubular antigens. I. The natural history: A histologic and immunohistologic study at the light microscopy and the ultrastructural level. Lab Invest 32:235-242.

Hebert LA, Cosio FG, and Birmingham DJ (1992). The role of complement system in renal injury. Semin Nephrol 12:408427.

Heymann W, Hackel DB, Harwood S, Wilson SGF, and Hunter JLP (1959). Production of nephrotic syndrome in rats by Freund's adjuvants and rat kidney suspensions. Proc Soc Exp Biol Med 100:660-664.

Higgins PJ, Jone-Long K, Lobell R, Sardonini C, Alessi MK, and Yeh CG (1997). A soluble chimeric complement inhibitory protein that possesses both decay-accelerating and factor I cofactor activities. J Immunol 158:2872-2881.

Hopsu-Havu VK and Glenner GG (1966). A new dipeptide naphthylamidase hydrolyzing glycyl prolyl-betanaphthylamide. Histochemie 7:197-201.

wata S, Yamaguchi N, Munakata Y, Ikushima H, Lee JF, Hosono O, Schlossman SF, and Morimoto C (1999). CD26/ dipeptidyl peptidase IV differentially regulates the chemotaxis of $T$ cells and monocytes toward RANTES: Possible mechanism for the switch from innate to acquired immune response. Int Immunol 11:417-426.

Johnson RJ (1997). Involvement of complement components in renal disease. Curr Opin Nephrol Hypertens 6:120-127.

Kurihara H, Sunagawa N, Kobayshi T, Kazuhiro K, Takasu N, and Shike T (1998). Monoclonal antibody P-31 recognizes a novel intermediate filament-associated protein (p250) in rat podocytes. Am J Physiol 274:F986-F997.

Magee JC, Collins BH, Harland RC, Lindman BJ, Bollinger RR, Frank MM, and Platt JL (1995). Immunoglobulin prevents complement-mediated hyperacute rejection in swine-toprimate xenotransplantation. J Clin Invest 96:2404-2412.

Mendrick DL and Rennke HG (1988). I. Induction of proteinuria in the rat by a monoclonal antibody against SGP-115/ 107. Kidney Int 33:818-830.

Mizokami A, Eguchi K, Kawakami A, Ida H, Kawabe Y, Tsukada T, Aoyagi T, Maeda K, Morimoto C, and Nagataki S (1996). Increased population of high fluorescence 1F7 (CD26) antigen on T cells in synovial fluid of patients with rheumatoid arthritis. J Rheumatol 23:2022-2026.

Morimoto C and Schlossman SF (1998). The structure and function of CD26 in the T-cell immune response. Immunol Rev 161:55-70. 
Morimoto C, Torimoto Y, Levinson G, Rudd CE, Schrieber M, Dang NH, Letvin NL, and Schlossman SF (1989). 1F7, a novel cell surface molecule, involved in helper function of CD4 cells. J Immunol 143:3430-3439.

Morita $\mathrm{Y}$, Nomura A, Yuzawa $\mathrm{Y}$, Nishikawa K, Hotta N, Shimizu F, and Matsuo S (1997). The role of complement in the pathogenesis of tubulointerstitial lesions in rat mesangial proliferative glomerulonephritis. J Am Soc Nephrol 8:13631372.

Nangaku M, Meek RL, Pippin J, Gordon KL, Morgan BP, Johnson RJ, and Couser WG (1996). Transfected CD59 protects mesangial cells from injury induced by antibody and complement. Kidney Int 50:257-266.

Nangaku M, Quigg RJ, Shankland SJ, Okada N, Johnson RJ, and Couser WG (1997). Overexpression of Crry protects mesangial cells from complement-mediated injury. J Am Soc Nephrol 8:223-233.

Natori Y, Hayakawa I, and Shibata S (1986). Passive Heymann nephritis with acute and severe proteinuria induced by heterologous antibody against renal tubular brush border glycoprotein gp108. Lab Invest 55:63-70.

Natori Y, Hayakawa I, and Shibata S (1987). Identification of gp108, a pathogenic antigen for experimental immune complex glomerulonephritis, as dipeptidyl peptidase IV. Clin Exp Immunol 70:434-439.

Natori Y, Hayakawa I, and Shibata S (1989). Role of dipeptidyl peptidase IV (gp108) in passive Heymann nephritis: Use of dipeptidyl peptidase IV-deficient rats. Am J Pathol 134: 405-410.

Ogata S, Misumi Y, and Ikehara Y (1989). Primary structure of rat liver dipeptidyl peptidase IV deduced from its CDNA and identification of the $\mathrm{NH} 2$-terminal signal sequence as the membrane-anchoring domain. J Biol Chem 264:3596-3601.

Oya H, Nagatsu I, and Nagatsú T_(1972). Purification and properties of glycylprolyl-naphthylamidase in human submaxillary gland. Biochim Biophys Acta 258:591-599.

Quigg RJ, He C, Lim A, Berthiaume D, Alexander JJ, Kraus D, and Holers VM (1998). Transgenic mice overexpressing the complement inhibitor Crry as a soluble protein are protected from antibody-induced glomerular injury. J Exp Med 188: 1321-1331.

Reinhold D, Bank U, Buhling F, Lendeckel U, Faust J, Neubert K, and Ansorge S (1997). Inhibitors of dipeptidyl peptidase IV induce secretion of transforming growth factor- $\beta 1$ in PWM-stimulated PBMC and T cells. Immunology 91:354-360.

Reinhold D, Bank U, Buhling F, Neubert K, Mattern T, Ulmer AJ, Flad HD, and Ansorge S (1993). Dipeptidyl peptidase IV (CD26) on human lymphocytes: Synthetic inhibitors of and antibodies against dipeptidyl peptidase IV suppress the proliferation of pokeweed mitogen-stimulated peripheral blood mononuclear cells, and IL-2 and IL-6 production. Immunobiol 188:403-414.
Shinosaki T, Notoya M, Nomura Y, Miyai I, Kobayashi T, and Kurihara H (In press, 2002). Glomerular epithelial cell injury accelerates the progression of antibody-induced mesangial proliferative nephritis. Exp Nephrol 10

Steinbrecher A, Reinhold D, Quigley L, Gado A, Tresser N, Izikson L, Born I, Faust J, Neubert K, Martin R, Ansorge S, and Brocke S (2001). Targeting dipeptidyl peptidase IV (CD26) suppresses autoimmune encephalomyelitis and upregulates TGF- $\beta 1$ secretion in vivo. J Immunol 166:20412048.

Svensson B, Danielsen M, Staun M, Jeppesen L, Noren O, and Sjostrom H (1978). An amphiphilic form of dipeptidyl peptidase IV from pig small-intestinal brush-border membrane: Purification by immunoadsorbent chromatography and some properties. Eur J Biochem 90:489-498.

Tiruppathi C, Miyamoto Y, Ganapathy V, Roesel RA, Whitford GM, and Leibach FH (1990). Hydrolysis and transport of proline-containing peptides in renal brush-border membrane vesicles from dipeptidyl peptidase IV-positive and dipeptidyl peptidase IV-negative rat strains. J Biol Chem 265:14761483.

Wallenstein S, Zucker CL, and Fleiss JL (1980). Some statistical methods useful in circulation research. Cir Res 47:1-9.

Watanabe Y, Kojima T, and Fujimoto Y (1987). Deficiency of membrane-bound dipeptidyl aminopeptidase IV in a certain rat strain. Experientia 43:400-401.

Weisman HF, Bartow T, Leppo MK, Marsh HC Jr, Carson GR, Concino MF, Boyle MP, Roux KH, Weisfeldt ML, and Fearon DT (1990). Soluble human complement receptor type 1: In vivo inhibitor of complement suppressing post-ischemic myocardial inflammation and necrosis. Science 249:146151.

Yamada K, Hori Y, Hanafusa N, Okuda T, Nagano N, ChoiMiura N, Couser WG, Miyata T, Kurokawa K, Fujita T, and Nangaku M (2001). Clusterin is up-regulated in glomerular mesangial cells in complement-mediated injury. Kidney Int 59:137-146.

Yamamoto T and Wilson CB (1987). Complement dependence of antibody-induced mesangial cell injury in the rat. J Immunol 138:3758-3765. 